\title{
Erratum zu: Grundlagen der Hubschrauber-Aerodynamik
}

Erratum zu:

B.G. van der Wall, Grundlagen der Hubschrauber-Aerodynamik, VDI-Buch https://doi.org/10.1007/978-3-662-60365-9

Für die Kapitel 2 Grundlagen der Drehflügleraerodynamik, 3 Die Blattelemententheorie, 4 Die Bewegung rotierender Flügel und 5 Leistungsberechnung im stationären Flug wurde elektronisches Zusatzmaterial bereitgestellt. Dieses kann auf der Springerwebseite unter dem jeweiligen Kapitel abgerufen werden.

Die aktualisierten Versionen der Kapitel können hier abgerufen werden:

https://doi.org/10.1007/978-3-662-60365-9_2

https://doi.org/10.1007/978-3-662-60365-9_3

https://doi.org/10.1007/978-3-662-60365-9_4

https://doi.org/10.1007/978-3-662-60365-9_5 